\title{
Preface
}

\section{Precision Medicine in the \\ Field of Sleep Medicine: Early \\ Days}

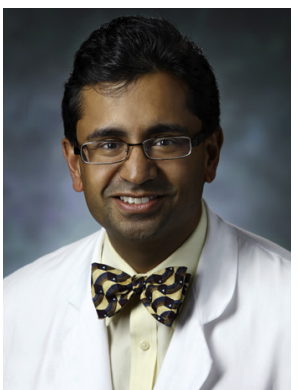

Susheel P. Patil, MD, PhD

Editor

The term "precision medicine" has gained popularity in recent years, particularly when the Obama administration announced its "Precision Medicine Initiative" in 2015, which included focused investments in a national research cohort, identifying genetic drivers in cancer, and modernizing the regulatory landscape to support such research while maintaining privacy. ${ }^{1}$

The National Research Council ${ }^{2}$ defined precision medicine as:

... the tailoring of medical treatment to the individual characteristics of each patient. It does not literally mean the creation of drugs or medical devices that are unique to a patient, but rather the ability to classify individuals into subpopulations that differ in their susceptibility to a particular disease, in the biology and/or prognosis of those diseases they may develop, or in their response to a specific treatment. Preventive or therapeutic interventions can then be concentrated on those who will benefit, sparing expense and side effects for those who will not. Although the term "personalized medicine" is also used to convey this meaning, that term is sometimes misinterpreted as implying that unique treatments can be designed for each individual.

Much of the focus has been on creating largescale data sets in areas such as cancer on which big data analytics might be applied to gain insights into different disease phenotypes or phenotypebased responses to treatment. The field of sleep medicine is arguably in the beginning stages of utilizing such an approach to tailor treatments for patients. Some areas of sleep medicine such as obstructive sleep apnea have potential tools ${ }^{3,4}$ that can be used as part of a strategy for "deep phenotyping" 5 of patients that needs to be implemented to address precision medicinerelated questions. Similarly, areas such as chronic insomnia, individual responses to sleep restriction, and restless legs syndrome show potential promise for applying precision medicine approaches with the identification of genetic markers and application of our understanding of the pharmacogenetics of commonly used medications in sleep medicine. Other areas of sleep medicine, such as idiopathic hypersomnia or some parasomnias, are possibly at an earlier stage for application of precision medicine given the rarity of these disorders.

In this issue of Sleep Medicine Clinics entitled, "Precision Sleep Medicine," a collection of articles has been assembled, written by distinguished experts, that address where our field currently is with respect to precision medicine principles for many sleep disorders. Regrettably a few important areas are absent from this issue, which should not be construed as precision medicine approaches that are absent in these areas. I 
would like to thank the contributors to this issue who have created content that should be stimulating to readers and help inform continued discussions of precision medicine within the field of sleep medicine.

\section{Susheel P. Patil, MD, PhD Division of Pulmonary and Critical Care Medicine Johns Hopkins Sleep Disorders Center Asthma and Allergy Center 5501 Hopkins Bayview Circle \\ Room 4B.50 \\ Baltimore, MD 21224, USA \\ E-mail address: spatil@jhmi.edu}

\section{REFERENCES}

1. Fact Sheet: President Obama's Precision Medicine Initiative. The Obama White House Web site. January
30, 2015. Available at: https://obamawhitehouse. archives.gov/the-press-office/2015/01/30/fact-sheetpresident-obama-s-precision-medicine-initiative. Accessed June 3, 2019.

2. Committee on a Framework for Development a New Taxonomy of Disease. National Research Council of the National Academy of Science. Toward precision medicine: building a knowledge network for biomedical research and a new taxonomy of disease. National Academies Press; 2011. Available at: http://www.nap. edu/catalog.php?record_id=13284. Accessed June 3, 2019.

3. Eckert DJ, White DP, Jordan AS, et al. Defining phenotypic causes of obstructive sleep apnea. Identification of novel therapeutic targets. Am J Respir Crit Care Med 2013;188(8):996-1004.

4. Ye L, Pien GW, Ratcliffe SJ, et al. The different clinical faces of obstructive sleep apnoea: a cluster analysis. Eur Respir J 2014;44(6):1600-7.

5. König IR, Fuchs $O$, Hansen $G$, et al. What is precision medicine? Eur Resp J 2017;50(4):1-12. 